\title{
Engineering Education across Disciplines and Cultures: A Mexico/USA Industrial Outreach Program
}

\author{
Alejandro Lozano ${ }^{1}$ \\ Council of Science and Technology of \\ Queretaro, Mexico \\ Elisabeth Sanchez ${ }^{2}$ \\ Educational Leadership Studies \\ West Virginia University, USA \\ Victor H. Mucino ${ }^{3}$ \\ Mechanical and Aerospace Engineering \\ West Virginia University
}

\begin{abstract}
West Virginia University and the Council for Science and Technology of Queretaro, Mexico, have launched an Engineering School-Industry Outreach Program in which students and faculty from the USA and Mexico reciprocate visits in order to team up and "work together" in industrial projects in realistic professional settings. Students from both universities get credit from their home institution and are assessed based on their engineering performance on each project, despite the evident cultural, language and environmental differences between people, universities and industries from both countries. While the main objective is to bring an international dimension to engineering education a proactive approach brings new perspectives to industry and academia from which new lessons have been learned.

For the participating students it was made clear from the start, that they would be assessed based on their engineering performance, as opposed to language proficiency, but they would be required to "communicate" and get across to get the job done in a timely and professional manner.

The industrial exposure and the cross-cultural interaction between students, industrial practitioners and faculty from both countries, provided the frame for a rather rich experience, in which each participant has a meaningful role and a potential benefit to draw. Many lessons can be drawn. However, while the main benefits are yet to come, one thing is certain; the cultural differences indeed exist, yet, students in the USA and in Mexico share much in common and being able to overcome these differences was not only possible, it was highly rewarding and yes,...quite fun!
\end{abstract}

\footnotetext{
${ }^{1}$ Director, Council of Science and Technology of Queretaro (CONCyTEQ)

${ }^{2}$ Doctoral Student, Educational Leadership Studies - International Education

${ }^{3}$ Associate Professor

Proceedings of the 2001 American Society for Engineering Education Annual Conference \& Exposition Copyright (C) 2001, American Society for Engineering Education
} 


\section{Introduction}

To bring the international and multicultural dimension to engineering education is easier said than done. One reason is the fact that most engineering courses are quite intense and rigid (and with good reason). There seems to be little time left to address globalization issues, trans-cultural communication or leadership traits in engineering education. Yet, in the professional world out there, the situation is quite different. Industry does not have time to think about globalization or leadership skills. They are fully immersed in it, and engineers in industry are making things happen. Simply put, it's just a matter of survival. In spite of this, the "School-Industry" relationship, despite its acknowledged importance, continues to be weak.

It has been acknowledged that University and Industry possess very different cultures. One is conservative, traditionalist and individualistic, the other is adaptive, progressive and emphasizes "team work". The way success is measured in academia for example is quite different from than in industry. In the former, publications, awards, research funding and teaching evaluations are the standard measures of individual achievement, whereas in industry, it is leadership, the ability to contribute to a team effort and ultimately, the ability to get the right things done at the right time are the measures of success.

Leaders from Industry have expressed concerns about the deficiencies of engineering graduates, citing specifically the following: communication skills, the ability to work in teams, flexibility, the ability to accept ambiguity comfortably, the ability to work with people form diverse backgrounds, understanding of globalization and its implications, and adequate ethics training [1]. These issues, among others, are also addressed in the ABET-2000 Engineering Criteria [2].

It is obvious that academia and industry share the responsibility, the challenge and the opportunity of producing top quality graduates in order to become and stay competitive. And that is the key issue, competitiveness.

The challenge comes at a time in which globalization trends demand innovative approaches to new and traditional technological needs as discussed by Jones [3]. One such challenge is producing graduates that can perform effectively and comfortably in international engineering scenarios; being able to communicate, to understand, and most important, to anticipate situations to make a difference in their professional environment [4]. Problems of technology development, trade, technology transfer and technology adaptation in North America and the world, are very closely related to the above mentioned challenges of Engineering Education.

Being aware of the aforementioned issues, West Virginia University (WVU) and Queretaro's Council for Science and Technology (CONCyTEQ) have developed a program, which is the object of this document. The program seeks to bring the 
international and industrial dimension to upper undergraduate engineering levels in a multidisciplinary and multicultural environment and addresses the following issues:

- To provide industrial exposure to students in an international and multicultural professional setting.

- This program seeks to bring the synergy of students, faculty and industrial practitioners together in meaningful engineering exercises.

- This program seeks to provide students a closer look at international industrial corporate dynamics, and simultaneously, to provide multinational corporations with prospective employees with a better understanding of international engineering operations.

The objectives of this initiative and program are consistent with the mission of the institutions involved and with the international outreach strategies of the participating industries.

\section{Objectives}

The overall objective of this program is to bring the international dimension to engineering education, in order to respond to the demands in industry, at a time in which globalization issues are more than a trend. It is felt that engineers can provide a better service to society and their profession, by understanding their role in the context of a global economy and trade partnership. Specifically the objectives are:

- To add value to the education of engineering graduates (above and beyond the good quality education they obtain in their respective programs). This can be achieved by providing meaningful exposure to industrial practices and technocultural idiosyncrasies in an international context.

- To conduct meaningful industrial exercises that leave value to industry. This is to be done under the synergy of "team-work" dynamics.

- To improve employment opportunities for engineering graduates. Students that participate in this program will have international technical experience and the opportunity to establish a relationship with Multinational Corporations.

- To expand WVU and CONCyTEQ horizons at both, national and the international levels by attracting students to this program and by providing meaningful, innovative and exciting opportunities for industry and professionals in the field.

- To get academia (faculty, research associates and students) closer to industry, and to explore technology development opportunities in collaboration with international institutions.

Proceedings of the 2001 American Society for Engineering Education Annual Conference \& Exposition Copyright (C) 2001, American Society for Engineering Education 
This program also provides a vehicle to Industry and its practitioners to bring meaningful and practical insight to academia and provides a mechanism to further expand professional development of engineering practitioners.

\section{Program Description}

This program [5] is directed at students, faculty and industrial practitioners in the USA, and Mexico, to collaborate in engineering education, in technology development and technology transfer exercises. The Program brings together students, faculty and industrial practitioners from the two countries, to team them up and conduct projects in industry (as course work for the students), via reciprocal term-long visits. In these visits students are teamed-up in small intermixed groups, and taken to industrial sites in the region of the host institution in turn. The main purpose is to conduct industrial projects under the guidance of faculty (from the visiting and host institutions) and industrial liaisons or monitors. Fig. 1. below, serves to illustrate the areas where results are sought in bringing the international dimension to education, mainly, opportunities for all involved.

Industry representatives present to each student team, a project outlining technical issues of a problem to solve. The host institution and industry provide the means for the student/faculty teams to formulate and develop a work plan leading to conclusive results and recommendations. Students and faculty from both countries are required to work together (thereby getting exposed to each other's cultural work idiosyncrasies) in order to submit reports and professional presentations to the industrial sponsors, on the findings of such projects. The reporting activity is carried out at the end of the semester in the form of a "Student Seminar", with the attendance of faculty and the industrial liaisons.

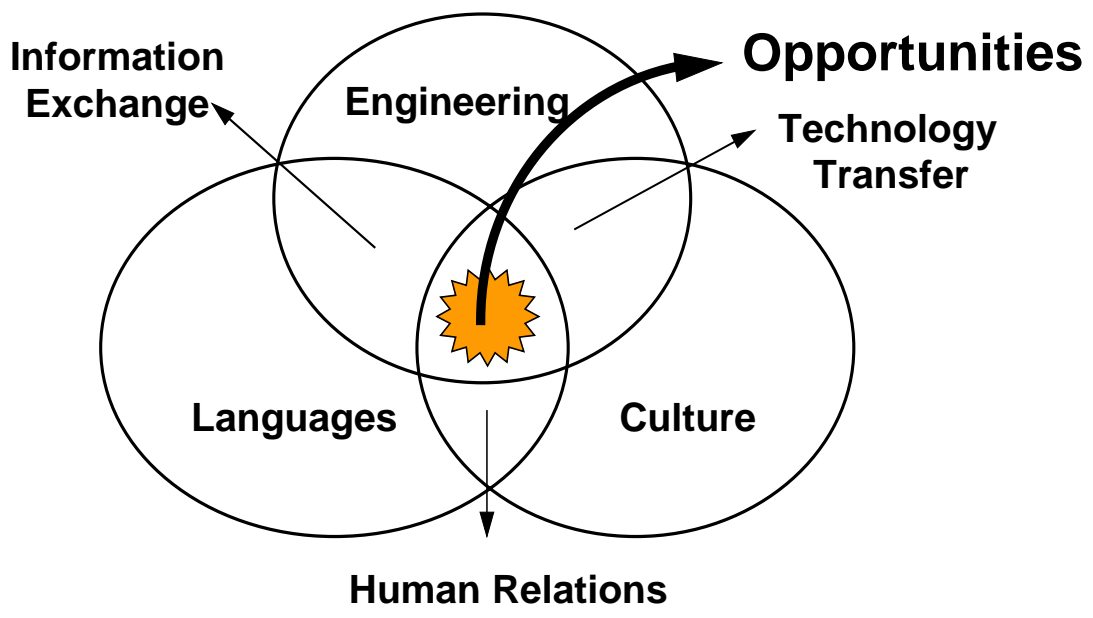

Fig. 1 Opportunities by bringing the international dimension to engineering education

Proceedings of the 2001 American Society for Engineering Education Annual Conference \& Exposition Copyright (C) 2001, American Society for Engineering Education 
The "industrial projects" are the highlight of the program but they offer the opportunity of additional courses directed at cluster requirements, such as languages, history or courses of social content during their stay, all of this while maintaining the intermixed nature of the academic activity.

Students are given credit in their home institution while the courses are basically team-taught by the faculty of the two institutions. In this program industrial projects are sought that have a multi-disciplinary element to it, such as mechanical-industrial, or aerospace-mechanical, or civil-mechanical-industrial. Some times, the projects address technology transfer issues and/or technology import/export problems. These courses fall in the category of "technical electives", which are offered to senior students in mechanical, industrial and civil engineering. In these courses, students learn the theoretical and practical aspects of the various disciplines, which in turn can be applied to the industrial projects.

Ideal cluster courses are those that address topics of interest to the students from the visiting and the host institutions. For example: "Industrial Corporate Dynamics in North America, "Modern History of North America Relations", "Free Trade and Technology Development" and "Multiculturalism in North America" among others.

Students pay tuition fees and get credit at their home institution. The home institution instructor is responsible for grading etc. The courses offered to students are developed and shared by faculty of the two institutions in reciprocating visits. Industrial participants, have access to data and material produced in the industrial projects, and also to some of the facilities (labs and computers) of the universities involved, through the project teams. Courses offered under this program are regular courses from the engineering curricula, that is, courses that can stand on their own with or without this Program in place.

\section{Industrial Projects}

In this program, it is intended for the industrial projects to involve industries that maintain some technical relation (commercial or corporate) with companies in the USA, and the project will deal with some aspects related to technology adaptation, transfer and development. Engineering projects that involve trade issues and/or language adaptation would be ideal in terms of exposing students first hand to some globalization issues in engineering.

Representatives from each participating company will add the realistic perspective while engaging themselves in the process of communication across cultures and disciplines. A student seminar is the closing event of the program, this seminar provides industrial liaisons with the opportunity of expanding further their vision while maintaining their focus on their professional areas of interest.

Proceedings of the 2001 American Society for Engineering Education Annual Conference \& Exposition Copyright (C) 2001, American Society for Engineering Education 
The projects often involve the application of advanced computer aided design technologies for the modeling, analysis and design of mechanical and/or structural systems. The student advisors (instructors of the course) have had experience in $\mathrm{CAD} / \mathrm{CAM}$ instruction and in the actual application of these tools.

\section{Lessons Learned}

There is something to be said about acquiring an appreciation for another culture and discipline by just being "exposed" to it. But nothing compares to having the "need to get the job done", in order to gain a better understanding of the different approaches to similar objectives in two different environments.

To share the experience gained in this program, some comments and perspectives from participating students are in order. The following are several comments by students upon completion of the program, taken from Ref.[6]

- "As a result of my experience, I won't be afraid to take risks, to do things that are out of my routine. I won't be as apprehensive. I would like to travel, see new places. I have a desire to see more of the world and learn what I know and what is there."

- "I would advice other students to take the risk. I had a tendency to be apprehensive when leaving the United States, but this program is worthwhile. I did not experience many drawbacks or negatives to the program. It is a positive experience for future employment."

- "I learned professionally speaking, that there is more involved than the actual engineering project. You have to be able to deal with people. Also, personal things happened during the trip that affected the project and I guess I learned from these experiences and from these mistakes. It made me a more rounded experienced person."

- "Working in a team helped me understand the differences in personality, strengths and weaknesses. It is a good example of what it is going to be like in the work place. In addition the program will stand out in my resume when I go seeking a job; I will have something to talk about in a job interview."

- "I realized that people learn and communicate differently. The information is conveyed in a different manner. It differs from country to country. You need to be sure that you understood fully otherwise you can get the wrong idea."

- "As far as communication is concerned, it is a little bit more difficult to work here (Mexico) than back home (U.S.A) because of the language. However,

Proceedings of the 2001 American Society for Engineering Education Annual Conference \& Exposition Copyright (C) 2001, American Society for Engineering Education 
miscommunication is not so much of a problem. The differences add a different dimension, perspective. It makes it more interesting."

- "Someone who is not open to change should not participate to the program. In Rome do as Romans do. You have to adopt this philosophy. This is a very valuable experience from a cultural and engineering points of view. Also from the personal life experience."

- "I have more appreciation for other cultures on this continent, not that I didn't have any before, but now it is almost larger than life. I have a better understanding of what makes Mexico and United States different which is very fascinating."

From the perspective of the faculty, two benefits can be brought forward, one is the "closeness" to students developed through the program; the second one is the "closeness" to industry. Indeed, peer support from countrymen and fellow students from the other country provided an added dimension to student-to-student relations. Instructor's guidance on issues ranging from cultural to technical questions provided an opportunity of a more wholistic and personal communication. The relationship between the industrial practitioner and both students and faculty provided also new dimensions, in which everyone involved had something to share. One of the faculty leaders in this program had the following comments:

- "The relation between student and faculty in this program is perhaps more similar to that of a basketball team and a coach. The important thing is to win as a team, and the coach is part of the team, except that in doing this, nobody is to loose"

- "One of the most important lessons for me as an instructor is to see how the differences in personalities and cultures have an impact on the performance of the team. In deed, cultural issues can be the difference between success and failure"

- "In the professional world people can not leave their cultures and values in the door. They carry them all the time, and the differences come up when they deal with pressure, with a different sense of time dimension, with expressing disagreement"

- "Some of the students project a self assurance, that sometimes becomes aggressiveness. In contrast, some students are so polite, that they become shy out of respectfulness"

- "The industrial liaisons were skeptical at the beginning. They were afraid we would make them waste their time, but now, they have realized that they can team up with us and get value out of our activity. We have started to play more like a basketball team"

Proceedings of the 2001 American Society for Engineering Education Annual Conference \& Exposition Copyright (C) 2001, American Society for Engineering Education 
Finally from the industrial perspective, the benefits are yet to be realized. Thus far, participating industries have become more comfortable with the concept of this program as the projects have yielded some positive results. But this program leaves behind more than "results", it leaves a cultural experience for the industrial participants which is starting to sink in. This program shows that the concept is a viable one and the potential exists to bring a direct benefit to industry and to all involved.

\section{Conclusions}

Cultural differences indeed exist in industry, in academia and in the peoples of different countries. These differences are reflected in the way people deal with time, with pressure, with leadership, with deadlines. Also in the way people approach social issues and nowadays, global issues.

The internationalization of engineering curriculum has become a necessity, and while it is important to identify the reasons why it should be done, to provide answers to the how to do it is at the very heart of the challenge of bringing the international dimension to engineering education. In this paper, a concept is put forward, to provide an example of how the international dimension is being brought to the engineering curricula in two institutions, with a minimum of curricular changes. As a matter of fact, these can be viewed more as curricular adaptations rather than changes.

While this program initially targets mechanical, industrial and civil engineering students, it is quite likely that this program will expand to other areas of interest such as robotics, machine tools, electronics etc.. Most importantly, this program may possibly expand to involve other universities in Mexico and later on in Canada as well. Ultimately, the success of the program will depend on the difference that this program will make on the students and the industrial participants, as this program is meant to add value to the professional profile of all of those involved. Now the challenge is to carry on!!

\section{References}

1. Task Force on High-Performance Work and Workers: The Academic Connection. Spanning the Chasm: Corporate and Academic Cooperation to Improve Work-Force Preparation. Business- Higher Education Forum in Affiliation with the American Council on Education, January 1997, Washington, D.C. p.5

2. ABET, Engineering Criteria 2000, Third Edition, Engineering Accreditation Commission of the Accreditation Board of Engineering and Technology.

3. Jones R.C., "Educating Engineers for International Practice", Liberal Education, Fall-1995.

Proceedings of the 2001 American Society for Engineering Education Annual Conference \& Exposition Copyright (C) 2001, American Society for Engineering Education 
4. Viets, H., \& Grandin, J. "International Experience for Engineers", The International Journal of Engineering Education, Vol. 9 No. 1, 1993. pp 93-94

5. Mucino V.H., "An Initiative in Engineering Education Across Disciplines and Cultures: School-Industry Outreach in North America" URL: http://spline.mae.wvu.edu/ug/ug.html

6. Sanchez, E. y Vallejo-Jauregui F.J., "Un Programa de Alcance Industrial entre WV, Guanajuato y Queretaro: El Impacto en Estudiantes", Presented at the VIII Annual Meeting of AMPEI, Universidad Veracruzana, Mexico, November 13-16, 2000. (To appear in AMPEI's Global Education, Vol 5). 